BACKGROUND: Ozone as a strong oxidant may induce an inflammatory response.

Aim: The hypothesis was verified as to whether ozonated autohemotherapy using an ozone dose in therapeutic range changes the plasma concentration of C-reactive protein and interleukin-6, markers of inflammation.

Metbods: In a controlled, single-blind, cross-over study, 12 chronically hemodialyzed patients with peripheral arterial disease were exposed to nine sessions of autohemotherapy with blood exposure to oxygen as a control followed by nine sessions of ozonated autohemotherapy with an ozone concentration of $50 \mu \mathrm{g} / \mathrm{ml}$.

Results: There was no statistical difference between C-reactive protein levels at baseline $(1.53 \pm 1.01 \mathrm{mg} / 1)$, after nine sessions of control autohemotherapy $(1.48 \pm 0.96 \mathrm{mg} / 1)$, and after nine sessions of ozonated autohemotherapy $(1.55 \pm 0.84 \mathrm{mg} / \mathrm{l})$. There was also no statistical difference between the interleukin- 6 serum concentration at baseline $(438 \pm 118 \mathrm{pg} / \mathrm{ml})$, after nine sessions of control autohemotherapy $(444 \pm 120 \mathrm{pg} / \mathrm{ml})$, and after nine sessions of ozonated autohemotherapy $(466 \pm 152 \mathrm{pg} / \mathrm{ml})$.

Conclusion: The results of this study suggest that ozonated autohemotherapy using an ozone concentration of $50 \mu \mathrm{g} / \mathrm{ml}$ does not induce an inflammatory response.

Key words: Ozone, Ozonated autohemotherapy, Inflammation, C-reactive protein, Interleukin-6, Hemodialysis, Peripheral arterial disease

\section{No effects of ozonated autohemotherapy on inflammation response in hemodialyzed patients}

\author{
Leszek Tylicki ${ }^{1, C A}$, Bogdan Biedunkiewicz ${ }^{1}$, \\ Dominik Rachon², Tomasz Nieweglowski ${ }^{1}$, \\ Lukasz $\mathrm{Hak}^{2}$, Andrzej Chamienia ${ }^{1}$, Alicja Debska- \\ Slizien ${ }^{1}$, Ewa Aleksandrowicz ${ }^{3}$, Jolanta Mysliwska ${ }^{2}$ \\ and Boleslaw Rutkowski
}

1Department of Nephrology, Transplantology and Internal Medicine, ${ }^{2}$ Department of Immunology and ${ }^{3}$ Department of Clinical Nutrition, Medical University of Gdansk, ul. Debinki 7, 80-211 Gdansk, Poland

\author{
${ }^{\mathrm{CA}}$ Corresponding Author \\ Tel/fax: +48583461186 \\ E-mail: leszek.tylicki@amg.gda.pl
}

\section{Introduction}

Major ozonated autohemotherapy constitutes a complementary medical approach in the treatment of different disease states (reviewed in 1,2). The main criticism concerning this controversial therapy is associated with the oxidative properties of ozone and its potentially harmful influence on cells and biological processes. ${ }^{3}$ To gain more light into this issue, we commenced the clinical project aimed to check the safety of ozonated autohemotherapy (O3-AHT) in the treatment of ischemic complaints in hemodialyzed (HD) patients with peripheral arterial disease. O3-AHT applied in the therapeutic dose range according to Bocci's recommendations has been found not to cause either protein or lipid oxidative modification. ${ }^{4}$ Intravascular hemolysis, another possible side effect, was also not observed in the same study. We have also demonstrated that O3AHT does not have any deleterious effects on the endothelium nor promotes platelet aggregation. ${ }^{4,5}$ Other authors did not find any negative effects of ozone on white blood cell or red blood cell function. ${ }^{6,7}$
In the present study, the influence of O3-AHT on the inflammation process was evaluated in subjects on dialysis maintenance. These patients are particularly threatened by the development of inflammation. Renal failure per se may contribute to the inflammation response, which enhances as renal function declines, and is greatest still in patients on dialysis (reviewed in 8,9). Inflammation is considered an important non-traditional cardiovascular risk factor. Given that HD patients are at increased risk for cardiovascular complications, one has no doubt that any intervention that may potentially induce inflammatory response in these subjects needs particular attention.

\section{Patients and methods}

\section{Subjects}

Twelve chronically HD patients were enrolled to the study. They underwent regular bicarbonate HD treatment, three times per week. Their detailed characteristic have been presented elsewhere. ${ }^{10,11}$ All of them suffered from symptomatic peripheral 
arterial disease (stage II-III according to Fontain), which was the main reason for the implementation of O3-AHT. The HD prescription, namely dialyzer type, HD session length, rate of dialysis solution and blood flow, as well as any pharmacological treatment, were unchanged during the study and 2 months prior to the study commencement. Individuals with active chronic inflammatory disease and those with symptomatic or asymptomatic (as confirmed by laboratory tests; C-reactive protein [CRP] evaluation) acute infection were excluded from the study.

\section{Study design}

At the beginning subjects received nine sessions of autohemotherapy with blood exposure to medical oxygen (AHT) as a control, followed by nine sessions of O3-AHT. The procedures were performed three times a week in the early morning, just before the HD session, in a single blind manner. An ozone generator (ATO-3; Kriometrum, Warsaw, Poland) attested by the Polish Health Ministry was used in the study. The procedure of O3-AHT has been described elsewhere in detail. ${ }^{4,10,11}$ During O3-AHT sessions, $250 \mathrm{ml}$ of the patients' blood was exposed ex vivo to an oxygen-ozone mixture with an ozone concentration of $50 \mu \mathrm{g} / \mathrm{ml}$. Three blood samples were collected from all subjects at the following time-points: before the first session of AHT (first collection), after the ninth session of AHT (second collection - control) and after the ninth session of O3-AHT (third collection).

\section{Interleukin-6 bioassay}

Interleukin (IL)-6 levels in the sera were determined using the B9 hybrydoma proliferation assay. ${ }^{12}$ In this assay, $10 \times 10^{3}$ B9 cells (a gift from Dr L. Aarden, Netherland Red Cross, Amsterdam, The Netherlands) were cultured on a 96-well plate (NUNC $^{\mathrm{TM}}$; Roskilde, Denmark) with 50 times diluted samples of sera or supernatants in the final volume of $100 \mu \mathrm{l}$ of RPMI

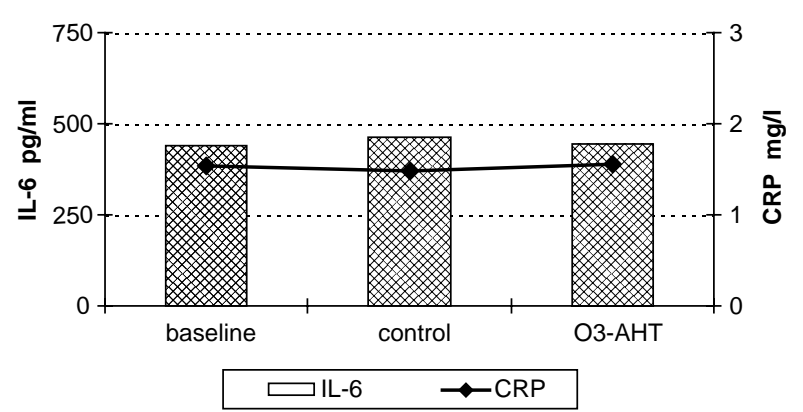

FIG. 1. CRP and IL-6 plasma concentrations after control autohemotherapy and after ozonated autohemotherapy (O3-AHT).
1640 (Gibco BRL, Life Technologies, Inc., Gaithersburg, MD, USA), supplemented with $5 \times 10^{-5} \mathrm{M}$ of 2mercaptoethanol (Sigma, Mannheim, Germany), 10\% fetal calf serum (Gibco BRL, Life Technologies, Inc.), $100 \mathrm{U} / \mathrm{ml}$ of penicilin and $100 \mu \mathrm{g} / \mathrm{ml}$ of streptomycin (Sigma). All samples were put on a 96-well plate in triplicate. After $48 \mathrm{~h}$ of incubation in a humidified atmosphere containing $5 \% \mathrm{CO}_{2}$ at $37^{\circ} \mathrm{C}, 20 \mu \mathrm{l}$ of MTT (Sigma) were added to each well of the plate. The plate was incubated for the next $4 \mathrm{~h}$ in the aforementioned conditions, and after this time $100 \mu \mathrm{l}$ of isopropanol (Sigma) were added. The optical density was read at $570 \mathrm{~nm}$ on the automated plate reader (Bio-Tek FL600; Bio-Tek Instruments, Inc. Winooski, Vermont, USA). A standard curve relating cell proliferation to doses of recombinant human IL-6 (Sigma) was used to quantify IL-6 activity in the samples.

To confirm the specificity of the test, the monoclonal anti-IL-6 antibody (Genzyme, Rüsselsheim, Germany) was added $(1: 10,1: 20,1: 50)$ to the samples. The anti-IL-6 monoclonal antibody completely inhibited the ability of the B9 cells to proliferate. This assay had a detection limit of $1 \mathrm{pg} / \mathrm{ml}$. The interassay coefficient of variation ranged between $9.5 \%$ and $10.9 \%$. The inter-assay coefficient of variation ranged between $15.2 \%$ and $17.7 \%$.

Serum concentrations of IL-6 were assessed using a specific sandwich enzyme-linked immunosorbent assay by R\&D Systems, Minneapolis, MN, USA. All samples were analyzed in triplicate. The amount of cross-reactivity was assessed by comparison with the concentration yielding a 50\% inhibition of binding. Sensitivity levels were between 0.3 and $3000 \mathrm{pg} / \mathrm{ml}$ (IL-6); intra-assay and inter-assay precision variability was $<3 \%$ (controls, data not shown). Enzyme-linked immunosorbent assay antibodies against IL-6 were used to absorb the cytokines from cell culture supernatants or sera.

\section{CRP assay}

CRP plasma level analysis was performed immunoturbidimetrically using a commercially available kit (Tina-quant CRP; Boehringer Mannheim, Germany) according to the manufacturer's instruction.

\section{Statistical analysis}

Data are expressed as means \pm standard deviations. Differences of variables were assessed by analysis of variance for repeated measurements. Data were evaluated using the STATISTICA software package (version 6.0; StatSoft Inc., Tulsa, OK, USA). 


\section{Results}

All of 12 patients who entered the study completed the protocol. During the study no patient demonstrated symptoms of acute infectious disease. The CRP serum level, analyzed as a marker of inflammation, was in the normal range throughout the study in all patients (0-9 $\mathrm{mg} / \mathrm{l})$. There were no statistical differences between CRP levels at baseline $(1.53 \pm 1.01 \mathrm{mg} / \mathrm{l})$, after nine sessions of control AHT $(1.48 \pm 0.96 \mathrm{mg} / \mathrm{l})$, and after nine sessions of O3-AHT $(1.55 \pm 0.84 \mathrm{mg} / \mathrm{l})$. There was also no statistical difference between IL-6 serum concentrations at baseline $(438+118 \mathrm{pg} / \mathrm{ml})$, after nine sessions of control AHT $(444 \pm 120 \mathrm{pg} /$ $\mathrm{ml})$, and after nine sessions of O3-AHT (466 \pm 152 $\mathrm{pg} / \mathrm{ml})$.

\section{Discussion}

The investigation of systemic inflammation has been intensive in recent years, as it has been clearly shown that even low-level inflammation may be responsible for increased risk for cardiovascular disease in individuals with as well as without renal failure. ${ }^{13}$ Markers of inflammation such as CRP and IL-6 powerfully predict death from all causes and from cardiovascular disease. ${ }^{14}$ The underlying mechanisms of such deleterious consequences of inflammation involve vascular injury and malnutrition. It has been clearly demonstrated that inflammation, by suppressing synthesis or increasing catabolic rates of albumin, transferrin, and other negative acute-phase proteins, either combines with modest malnutrition or mimics malnutrition. More importantly, inflammation alters protein composition and endothelial structure and function so as to promote vascular disease. ${ }^{8,9}$

The generation of oxygen free radicals is known to be involved in the development of the systemic inflammatory response. In addition to their actions as noxious mediators generated by inflammatory cells, these molecules also play a crucial role contributing to the onset and progression of inflammation in distant organs. In the early stages of the inflammation process, free radicals exert their actions via activation of nuclear factors, such as nuclear factor-kappa- $\beta$ or activator protein- 1 , that induce the synthesis of cytokines. ${ }^{15}$ The fact that ozone dissolving in blood generates the production of free radicals such as hydrogen peroxide ${ }^{3}$ forms the background for the hypothesis that O3-AHT may also promote the inflammation.

The previous in vitro studies demonstrated that ozone induced secretion of proinflammatory cytokine IL-6 from human macrophages and lympho- cytes. ${ }^{16,17}$ Otherwise, there is no clinical studies on this point with respect to therapeutic use of ozone. To examine the effects of O3-AHT on in vivo inflammatory response, the CRP and IL-6 plasma concentrations were measured before and after nine sessions of O3-AHT in the study, using autohemotherapy along with oxygen exposure as a control. CRP, a short-lived acute-phase protein, was used as a non-specific but very sensitive marker of inflammation. We also analyzed plasma level of IL-6, a pleiotropic proinflammary cytokine that induces the synthesis of CRP in hepatocytes. ${ }^{14}$ The study clearly demonstrated that neither the CRP nor IL-6 levels changed after O3-AHT. The plasma concentration of CRP and IL-6 measured after nine sessions of O3-AHT did not differ from the CRP and IL-6 levels assessed after control AHT (Fig. 1). To our best knowledge, this is the first clinical study concerning the influence of O3-AHT on markers of inflammation. Given our results, one may conclude that O3-AHT in a dose of $50 \mu \mathrm{g}$ of ozone/ml of ozone-oxygen mixture did not induce an inflammatory response. One may hypothesize that it might be a consequence of the relatively low dose of ozone, which has previously been shown not to cause oxidative injuries in HD patients. $^{11}$ The possibility cannot be excluded that ozone-induced inflammation is attenuated with multiday exposure. ${ }^{18}$ The results of this study seem to further confirm the safety of O3-AHT treatment in patients chronically treated with HD.

\section{References}

1. Bocci V. Oxygen-Ozone Therapy. A Critical Evaluation, Dordrecht: Kluwer Academic Publishers, 2002.

2. Di Paolo N, Bocci V, Gaggiotti E. Ozone therapy. Int J Artif Organs 2004; 27: $168-175$

3. Ueno I, Hoshino M, Miura T, Shinriki N. Ozone exposure generates free radicals in the blood samples in vitro. Detection by the ESR spintrapping technique. Free Radic Res 1998; 29: 127-135.

4. Tylicki L, Biedunkiewicz B, Nieweglowski T, et al. Ozonated autohemotherapy in patients on maintenance hemodialysis: influence on lipid profile and endothelium. Artif Organs 2004; 28: 234-237.

5. Tylicki L, Lizakowski S, Biedunkiewicz B, et al. Platelet function unaffected by ozonated autohemotherapy in chronically hemodialyzed patients. Blood Coagul Fibrinolysis 2004; 15: 619-622.

6. Zimran A, Wasser G, Forman L, Gelbart T, Beutler E. Effect of ozone on red blood cell enzymes and intermediates. Acta Haematol 2000; 102: $148-151$.

7. Margalit M, Attias E, Attias D, Elstein D, Zimran A, Matzner Y. Effect of ozone on neutrophil function in vitro. Clin Lab Haematol 2001; 23: $243-247$.

8. Kaysen GA, Eiserich JP. Characteristics and effects of inflammation in end-stage renal disease. Semin Dial 2003; 16: 438-446.

9. Galle J, Seibold S, Wanner C. Inflammation in uremic patients: what is the link? Kidney Blood Press Res 2003; 26: 65-75.

10. Tylicki L, Biedunkiewicz B, Nieweglowski T, et al. Fistula function and dialysis adequacy during ozonotherapy in chronically dialyzed patients. Artif Organs 2004; 28: 515-519.

11. Tylicki L, Nieweglowski T, Biedunkiewicz B, et al. The influence of ozonated autohemotherapy on oxidative stress in hemodialyzed patients with atherosclerotic ischemia of lower limbs. Int J Artif Organs 2003; 26 : $297-303$.

12. Aarden LA, De Groot ER, Schaap OL, Lansdorp PM. Production of hybridoma growth factor by human monocytes. Eur J Immunol 1987; 17: 1411-1416.

13. Willerson JT, Ridker PM. Inflammation as a cardiovascular risk factor. Circulation 2004; 109: II2-II10. 
14. Rattazzi M, Puato M, Faggin E, Bertipaglia B, Zambon A, Pauletto P. C-reactive protein and interleukin- 6 in vascular disease: culprits or passive bystanders? J Hypertens 2003; 21: 1787-1803.

15. Closa D, Folch-Puy E. Oxygen free radicals and the systemic inflammatory response. IUBMB Life 2004; 56: 185-191.

16. Becker S, Quay J, Koren HS. Effect of ozone on immunoglobulin production by human B cells in vitro. J Toxicol Environ Health 1991; 34 $353-366$.

17. Arsalane K, Gosset P, Vanhee D, et al. Ozone stimulates synthesis of inflammatory cytokines by alveolar macrophages in vitro. Am J Respir Cell Mol Biol 1995; 13: 60-68.
18. Christian DL, Chen LL, Scannell CH, Ferrando RE, Welch BS, Balmes JR. Ozone-induced inflammation is attenuated with multiday exposure. Am J Respir Crit Care Med 1998; 158: 532-537.

\section{Received 26 July 2004}

Accepted 25 August 2004 


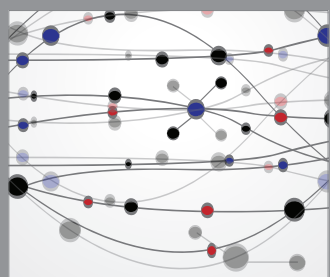

The Scientific World Journal
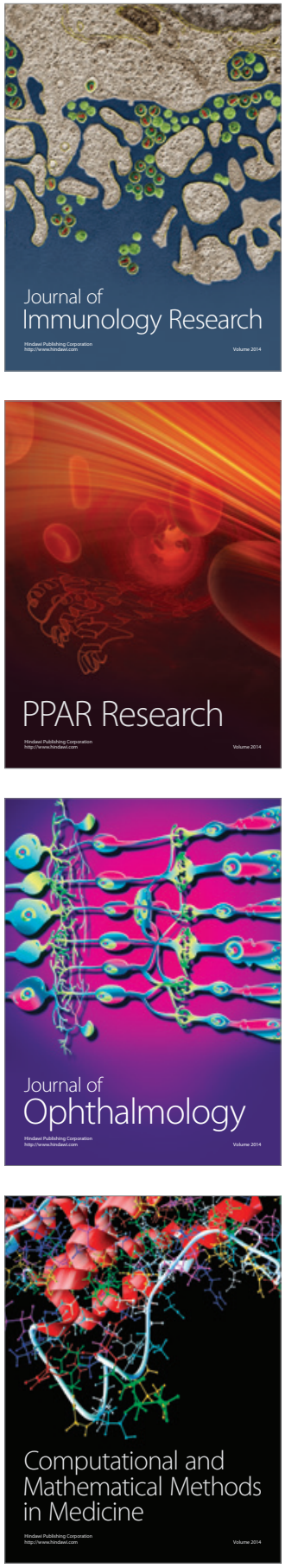

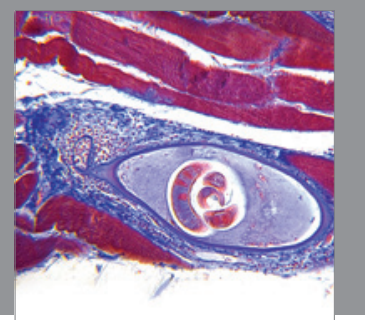

Gastroenterology

Research and Practice
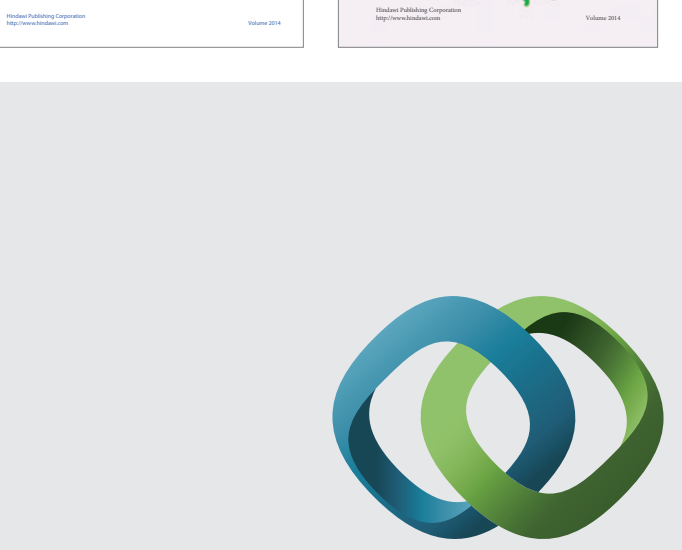

\section{Hindawi}

Submit your manuscripts at

http://www.hindawi.com
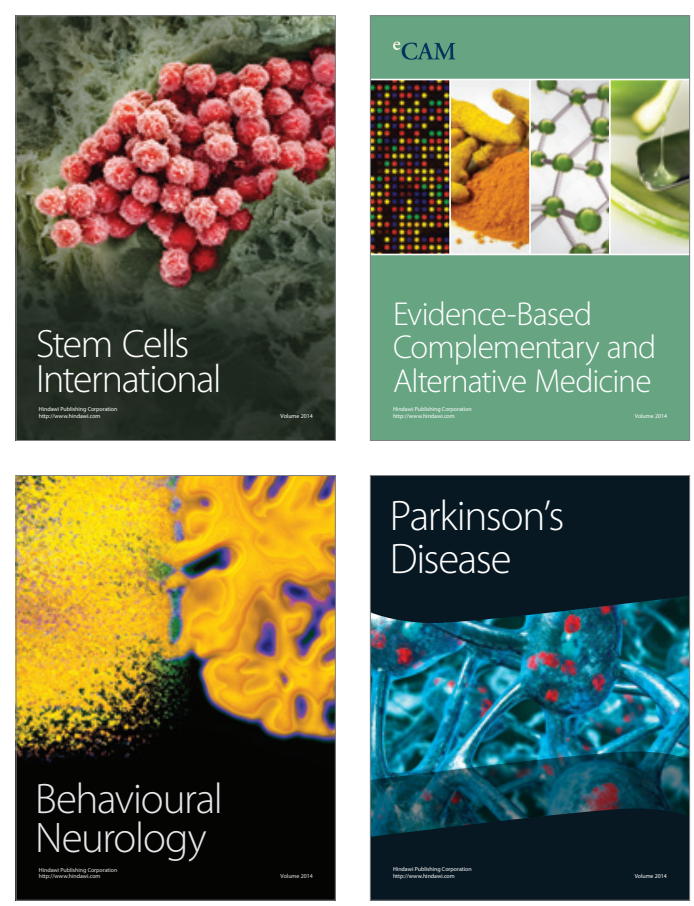

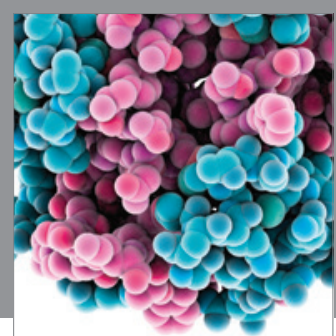

Journal of
Diabetes Research

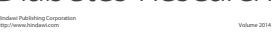

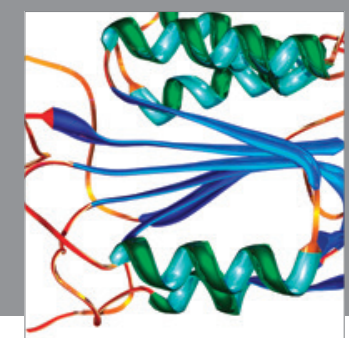

Disease Markers
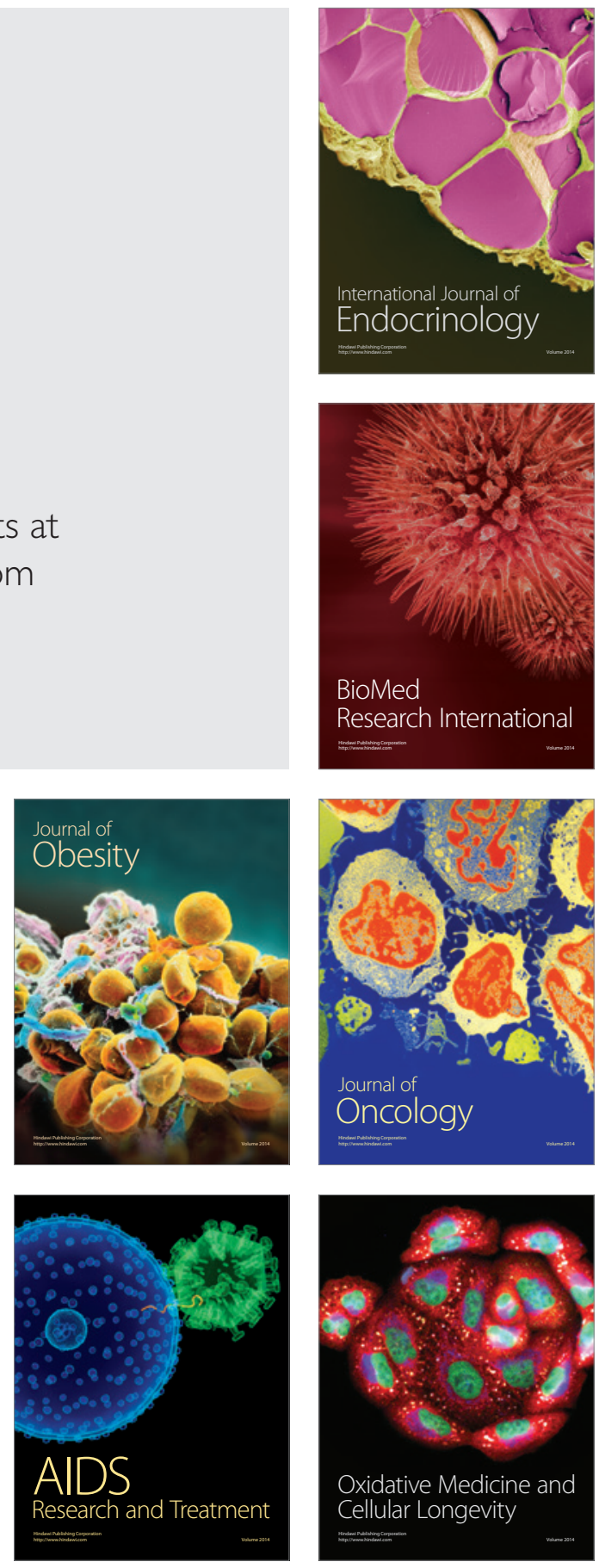